\title{
Rostos de criança com direitos nos espaços públicos: uma análise de documentos de domínio público
}

\author{
Carla Bertuol. ${ }^{1}$
}

RESUMO: A partir de uma perspectiva construcionista temos como objetivo estabelecer aproximações sobre os sentidos de criança usados para descrever os seus direitos. Para tanto utilizamos a análise de documentos de domínio público, concebidos como práticas discursivas e tomamos como material de análise cartas de direitos produzidas no contexto de organismos internacionais anteriores ao Estatuto da Criança e do Adolescente. A análise mostra configurações construídas a partir de definições de criança, prescrições sobre o modo como devem ser tratadas em suas relações sociais, inclusive pelo poder público, e de suas relações com os adultos, de maneira geral. Tais "rostos" de crianças podem trazer contribuições às negociações cotidianas em torno dos direitos das crianças e adolescentes nas práticas públicas, na atualidade.

PALAVRAS-CHAVE: Estatuto da Criança e do Adolescente, Infância, Direitos da Criança Produção de Sentidos. Discursos

ABSTRACT: Starting from a constructionist perspective we look for to establish approaches of child's meanings used to describe children's rights. According to this objective we used the analysis of documents in the public domain, conceived as discursive practices and took as material of analysis letters of rights produced in the context of international organisms prior to the Child and Adolescent Statute. The analysis shows configurations constructed from definitions of child, prescriptions on the way as they should be treated in their social relations, including the public power and of its relationships with the adults, in general. Such "faces" of children can bring contributions to the understanding of the daily negotiations in lathe to the children's and adolescent's rights in public practices, at the present time.

KEYWORDS: Statute of Child and Adolescent, Childhood, Children Rights, Production of meaning, Discourses.

\footnotetext{
1 Psicóloga. Doutora e Mestre em Psicologia Social pela PUC-SP. Docente e supervisora de estágios do curso de Psicologia da Universidade Católica de Santos. Psicóloga do Fórum de Santos. Especialista em Violência Doméstica contra a Criança e o Adolescente pelo IPUSP e em Psicoterapia Psicodinâmica Infantil pelo Instituto Sedes Sapientiae. Coordenadora do Centro de Valorização da Criança (1991-1996) da Secretaria Municipal de Saúde de Santos.e-mail: cbertuol@terra.com.br.Endereço residencial: rua Dr. Egydio Martins, 114 ap.11. Ponta da Praia - Santos - SP Cep 11030-160.
} 


\section{Introdução}

Estudiosos e militantes dos direitos das crianças (Boyden, 1995; Knutsson, 1995; Hammaberg, 1995; Seda, 1992) são unânimes em afirmar que o Estatuto da Criança e do Adolescente, que estabelece os direitos das crianças e adolescentes no Brasil, só será implementado quando seu conteúdo se tornar uma prática efetiva junto às crianças e aos adolescentes. Esta implementação é desejada e os conteúdos desta lei têm sido desde a sua promulgação, em 1990, norteadores das ações das políticas públicas de Assistência Social, Saúde e Educação, entre outras que têm buscado seguir as orientações emanadas deste documento para o seu estabelecimento no âmbito dos municípios, bem como da crescente implantação dos Conselhos de Direitos da Criança e do Adolescente municipais, estaduais e federal e dos Conselhos Tutelares.

O ECA materializa a assinatura do Brasil à Convenção Internacional dos Direitos da Criança da ONU, de 1989 e, nesta perspectiva, além da desejada democratização das práticas governamentais e públicas para a infância e adolescência em nosso país, também se aproxima de um outro processo social, ou de uma outra história, que é a própria história da infância ou, mais estritamente, da história de sua apresentação pública em documentos e normativas internacionais que tratam de descrever as crianças como portadores de direitos. Esta forma de apresentação das crianças e de seus direitos é relativamente recente e faz parte da longa construção social da infância tal como a vemos na atualidade. $\mathrm{O}$ historiador francês Philippe Áries foi o precursor de uma série de estudos sobre a infância. A partir da publicação do seu livro “A História Social da Criança e da Família” (1978/1981), houve um florescimento dos estudos sobre a infância que trataram de considerá-la como uma construção social. Neste livro ele nos mostra como o sentimento que temos hoje em relação à infância, um período da vida marcado pela idade, pela fragilidade e pela necessidade de proteção, não existia em outras épocas.

Podemos situar o aparecimento de leis e normativas sobre os direitos da criança num longo período de afastamento das crianças da vida de sociabilidade plena, período em que também ocorreram importantes mudanças econômicas e sociais que produziram a individualização e a institucionalização da criança na família e na escola. Tais documentos, internacionais, expressam uma orientação ampla para a sociedade em relação às crianças. 
A força e a intenção dos documentos internacionais emanam dos organismos que os produzem, como, por exemplo, a Convenção Internacional dos Direitos da Criança, de 1989, proposta pela ONU, cujos artigos os países signatários se comprometem a implementar, mediante a adequação das legislações locais. Também podemos encontrá-las na Declaração Universal dos Direitos da Criança (1959), bem como em momentos anteriores a esse tipo de organização.

Documentos de instituições relevantes como a Igreja Católica ou de organizações caritativas, tradicionalmente envolvidas com o cuidado e a assistência à infância, também podem trazer normativas que procuram refletir sobre a vida e os problemas das crianças. Assim, a carta encíclica Rerum novarum, de Leão XIII e a Declaração Internacional dos Direitos da Criança para a Liga das Nações, de 1924, proposta pela organização Save the Children, são documentos que têm explicitamente a mesma força e intenção de orientar as sociedades sobre como tratar as crianças. O mesmo ocorre em documentos que traduzem para a vida local as normativas internacionais, como o Estatuto da Criança e do Adolescente.

Esses documentos, ao mesmo tempo em que tentam estabelecer quais são os direitos da criança, fornecem uma definição da própria criança. Tal definição, ou melhor, tal busca de definição fundamenta as presunções de saber e de poder construídas nas ciências sobre a infância, especialmente enfatizadas durante o século $\mathrm{XX}$, e retrata também um processo mais longo de afastamento das crianças da vida da sociabilidade plena. Estes documentos internacionais apresentam fragmentos que nos ajudam a entender a construção do sentido de criança como titular de direitos, como cidadã.

Spink, P (1999) considera que os documentos de domínio público se definem pela característica de não serem privados e também por conterem o processo social de se tornarem públicos, isto é, eles apresentam as vozes que estão presentes no tema sobre o qual pretendem informar e apresentam estes diálogos em tempo, na interface do processo social de negociação no qual o público é produzido. Tais documentos são atores sociais na medida em que negociam sentidos circulantes e retratam possibilidades de ação com as crianças e os adolescentes.

A análise de documentos, estatutos e declarações internacionais pode contribuir, portanto, para esclarecer alguns aspectos do longo processo de construção da criança universal, na 
medida em que eles organizam um aspecto da experiência de ser criança ou de estar em contato com as crianças que faz sentido num determinado momento histórico, uma vez que documentos como esses são também produtores de sentido sobre a experiência de ser criança e de lidar com crianças.

A possibilidade de a criança ser apresentada na forma discursiva de documentos e estatutos tem mudado com o tempo, assim como as práticas sociais mudam. Desse modo, além de trazerem descrições importantes da conduta que confere sentido à proteção da infância, os termos que os diferentes documentos utilizam para definir as crianças também podem nos indicar quais são as versões de crianças que reúnem as condições de se assemelhar às que devem ser protegidas.

Além disto, podemos estabelecer diálogos com a perspectiva histórica a partir da Psicologia Social (Spink, P1999), usando-a como instrumento de análise do que tem presença viva na vida das pessoas (Braudel, 1992), e interrogar os direitos das crianças em relação a uma construção mais longa e atual da qual eles próprios são um elemento constitutivo. Dessa forma, entendemos que a diversidade dos conteúdos encontrados nos documentos internacionais encerra um processo temporal que pode ser compreendido de maneira atual e não simplesmente como uma evolução dos direitos da criança. Estamos diante de repertórios que estão disponíveis (Spink, M.J. 1999) para dar sentido à prática com crianças que têm direitos na atualidade.

Os documentos que analisamos foram: a Carta Encíclica Rerum novarum de 1859, a Declaração de Genebra de 1924 e a Declaração dos Direitos da Criança de 1959. A aproximação inicial destes documentos permitiu vislumbrar as definições de criança nas suas respectivas épocas históricas e também pôde revelar que, pouco a pouco, vão sendo construídas condutas em relação a ela, condutas que se aproximam do sentido do que deve ser de direito para as crianças.

Às vezes não é um documento ou uma série específica de documentos o que importa mas a presença ubíqua de uma temática nos documentos que serve como sinal para a desfamiliarização inicial. (Spink, 1999: 142)

Nestes documentos, algumas regularidades se apresentam: a primeira, talvez a mais importante, pela obviedade com que se apresenta no cotidiano, é a apresentação da criança 
como um ser destacado das suas relações sociais mais próximas e a descrição de uma ação centrada nela. A partir deste destacamento podemos nos aproximar da própria condição de construção da universalidade.

Segue-se então uma segunda regularidade: a questão de que os documentos sobre os direitos das crianças, suas disposições, argumentações e prescrições, tratam de proteger a criança. Entretanto, a proteção da criança, embora sempre presente, não se configura sempre da mesma maneira. Mostra-se diferente a cada vez, pois o espaço que as ações de proteção da criança ocupa é ampliado, com o tempo, em todas as relações estabelecidas com ela. Os documentos iniciais regulamentam sua presença nos espaços do trabalho, para mais tarde, como no capítulo "Da Prevenção" no Estatuto da Criança e do Adolescente, estabelecer os locais e espaços onde é possível ser criança. A proteção cresce e sua ação se expande para a vida na rua, na possibilidade de circulação. A criança, inicialmente protegida da situação de exploração no trabalho, passa a ser controlada e vigiada em praticamente todos os espaços sociais.

A terceira regularidade, também relacionada com as duas anteriores, é a presença de prescrições, formulação típica de leis. Elas nos dizem quais são as relações possíveis de serem estabelecidas entre adultos e crianças, além, é claro, de informar sobre o que é permitido e o que é proibido.

As cartas de direitos das crianças e adolescentes são assim, em tempo (Spink, P 1999), uma presença possível da história e da construção social da infância e das crianças tal como as vemos e condizente com a maneira com a qual nos relacionamos com elas. A criança universal está sendo construída a partir dessa separação do mundo dos adultos (tempo longo). Assim, embora possa constituir um campo discursivo único pela naturalidade com que aceitamos sua separação do mundo adulto, essa criança universal é construída e reconstruída por diferentes versões de crianças, presentes no cotidiano das práticas com as crianças. 


\section{A. A Encíclica Rerum novarum}

A Rerum novarum (sobre a condição dos operários) foi promulgada pelo papa Leão XIII em 15 de maio de 1891 e enuncia a posição da Igreja Católica sobre justiça social no final do século XIX. Foi escrita com o claro objetivo de tratar as questões envolvidas num "temível conflito" resultante dos problemas criados pela Revolução Industrial.

Mais do que um posicionamento da Igreja Católica sobre as "terríveis" e "imerecidas" condições em que se encontravam os operários, essa encíclica oficializa a visão das diferentes relações sociais, tais como: relações políticas (socialismo e liberalismo), família e Estado, governantes e governados, relações de classes (riqueza e o proletariado), associações de operários e patrões. Enfatiza o direito da Igreja de se pronunciar sobre as questões sociais ligadas a questões morais.

Fundamentando-se em referências bíblicas, no Antigo e no Novo Testamento, em Santo Tomás de Aquino e em pensadores cristãos do século II ao X, a encíclica aborda o tema do direito à propriedade privada à luz das condições modernas.

Mesmo não se tratando de um documento sobre crianças, a encíclica fala delas em alguns capítulos, sobretudo nos que aborda as relações entre família e Estado, a proteção do trabalho dos operários, das mulheres e das crianças, as obrigações e limites da intervenção estatal.

\section{A criança no capítulo que aborda as relações entre família e Estado}

Eis, pois, a família, isto é, a sociedade doméstica, sociedade muito pequena certamente, mas real e anterior a toda sociedade civil, à qual, desde logo, será forçosamente necessário atribuir certos direitos e certos deveres absolutamente independentes do Estado. Assim, este direito de propriedade que nós, em nome da natureza, reivindicamos para o indivíduo, é preciso agora transferi-lo para o homem constituído chefe de família. Isto não basta: passando para toda a sociedade doméstica, este direito adquire aí tanto mais força quanto mais extensão lá recebe a pessoa humana.

A natureza não impõe somente ao pai de família o dever sagrado de alimentar e sustentar seus filhos; vai mais longe. Como os filhos refletem 
a fisionomia de seu pai e são uma espécie de prolongamento de sua pessoa, a natureza inspira-lhe o cuidado do seu futuro e a criação de um patrimônio que os ajude a defender-se, na perigosa jornada da vida, contra todas as surpresas da má fortuna. (Rerum novarum, n. 19-20; grifos nossos).

O direito à propriedade privada é associado à criança, que é vista como um prolongamento do pai e o único desígnio para o sagrado direito do matrimônio. O casamento existe em decorrência da finalidade principal: "Crescei e multiplicai-vos". A criança constitui uma extensão do indivíduo, até mesmo semanticamente, e no texto passa a ser pessoa, com evidente elevação de seus atributos morais.

Está inscrita na Rerum novarum, portanto, como um elo, uma chave para um estado de coisas que vai desde a propriedade até a elevação na ordem social e divina.

Assim como a sociedade civil, a família, conforme atrás dissemos, é uma sociedade propriamente dita, com a sua autoridade e o seu governo paterno, é por isso que sempre indubitavelmente na esfera que the determina o seu fim imediato, ela goza, para a escolha e uso de tudo o que exigem sua conservação e o exercício de uma justa independência, de direitos pelo menos iguais aos da sociedade civil. (ibid., n. 19; grifos nossos)

Na encíclica, a criança, motivo sagrado da constituição da sociedade doméstica, está submetida à autoridade e ao governo do pai, assim como todos os membros que a compõem. Uma esfera delimita esse governo paterno: a esfera da sua finalidade. É a esfera da soberania do pai para a escolha e uso de tudo o que exige a conservação da família. Soberania em relação ao Estado e também em relação aos outros membros. A criança, como vimos, é considerada uma extensão do pai, e o capítulo que fala das relações entre a família e o Estado não cita diretamente a mulher ou a mãe.

Certamente, se existe algures uma família que se encontre numa situação desesperada e que faça esforços vãos para sair dela, é justo que, em tais extremos, o poder público venha em seu auxílio, porque cada família é um membro da sociedade. Da mesma forma, se existe um lar doméstico que seja teatro de graves violações dos direitos mútuos, que o poder público intervenha para restituir a cada um os seus direitos. Não é isto 
usurpar as atribuições dos cidadãos, mas fortalecer os seus direitos, protegê-los e defendê-los como convém. (ibid., n. 21)

A sociedade familiar constitui um membro da sociedade, em que a autoridade do pai só é invadida (pelo Estado) quando se trata de situações desesperadoras ou de violação dos direitos mútuos (relacionais). Para restituir a cada um os seus direitos, fortalecê-los, protegê-los e defendê-los como convém, faz-se necessária a intervenção do Estado. A conveniência, como veremos, é a da manutenção da ordem e do espaço familiar de indivíduos e de pessoas que formam os novos cidadãos.

A criança está incluída nas situações acima como portadora de direitos, relacionais e circunscritos ao universo dominado pelo pai.

A autoridade paterna não podia ser abolida nem absorvida pelo Estado, porque ela tem uma origem comum com a vida humana. "Os filhos são alguma coisa de seu pai"; são de certa forma uma extensão de sua pessoa, e, para falar com justiça, não é imediatamente por si que eles se agregam e se incorporam na sociedade civil, mas por intermédio da sociedade doméstica em que nasceram. O texto diz claramente que pais e filhos devem conviver natural e corporalmente, até que o livre-arbítrio os separe.

\section{A criança no capítulo “Obrigações e Limites da Intervenção do Estado”}

Ora, importa à salvação comum e particular que a ordem e a paz reinem por toda a parte; que toda a economia da vida doméstica seja regulada segundo os mandamentos de Deus e os princípios da lei natural. (ibid., n. 53; grifos nossos)

A vida doméstica deve ser regulada segundo os mandamentos da Igreja e as relações que se estabelecem na sociedade (entre as classes) devem respeitar esse princípio. É interesse de todos que não se degradem os sentimentos de religiosidade dos operários e que as relações sejam justas.

É por isso [...] que os patrões esmagam os trabalhadores sob o peso de ônus iníquos, ou desonram neles a pessoa humana por condições indignas e degradantes; que atentam contra a saúde por um trabalho excessivo e desproporcionado com a sua idade e sexo: em todos estes casos é 
absolutamente necessário aplicar em certos limites a força e a autoridade das lei. (ibid.; grifos nossos)

Embora o texto não nomeie explicitamente as crianças, elas podem ser incluídas nos casos em que condições indignas ou degradantes desonram a pessoa humana, submetendo-a a um trabalho excessivo e não proporcional à sua idade.

Os direitos, em que eles se encontram, devem ser religiosamente respeitados e o Estado deve assegurá-los a todos os cidadãos, prevenindo ou vingando a sua violação. Todavia, na proteção dos direitos particulares, deve-se preocupar, de maneira especial, com os fracos e indigentes. A classe rica faz das suas riquezas uma espécie de baluarte e tem menos necessidade da tutela pública. A classe indigente, ao contrário, sem riquezas que a ponham a coberto das injustiças, conta principalmente com a proteção do Estado. Que o Estado se faça, pois, sob um particularíssimo título, a providência dos trabalhadores, que em geral pertencem à classe pobre. (ibid., n. 54; grifos nossos)

O Estado deve ser, pois, providência para os pobres, para as crianças pobres que não podem frequientar a fábrica antes de amadurecer. E deve ser um guardião da ordem religiosa que estabelece diferenças entre ricos e pobres.

\section{A criança no capítulo "Proteção do trabalho das mulheres e das crianças"}

No que diz respeito aos bens naturais e exteriores, primeiro que tudo é um dever da autoridade pública subtrair o pobre operário à desumanidade de ávidos especuladores, que abusam, sem nenhuma discrição, das pessoas como das coisas. (ibid., n. 59)

A autoridade pública tem, por dever de justiça, de conter os abusos. Os argumentos da encíclica são todos voltados para a desumanidade das condições e o uso limitado das forças do ser humano para o trabalho, que impõem a necessidade de repouso, o respeito às características de tempo, compleição física e tipo de trabalho e às condições das estações do ano. 
Enfim, o que um homem válido e na força da idade pode fazer, não será eqüitativo exigi-lo de uma mulher ou de uma criança. Especialmente a infância - e isto deve ser estritamente observado - não deve entrar na oficina senão quando a sua idade tenha suficientemente desenvolvido nela as forças físicas, intelectuais e morais; do contrário, como uma planta ainda tenra, ver-se-á murchar com um trabalho demasiado precoce, e dar-se-á cabo da sua educação. (ibid., n. 60)

A criança está inserida nas relações de trabalho, embora essa inserção ocorra de forma diferente do adulto, especialmente do homem, uma vez que se estabelece como diferencial a força física. Ao falar da idade como tempo do desenvolvimento, a encíclica remete ao processo que ocorre nas plantas. Não existe um critério para se determinar a idade correta para a entrada da criança na oficina.

A criança se torna adulta quando ganha o livre-arbítrio e quando adquire força física, moral e intelectual. Estas não estão presentes na criança e caberá aos adultos cuidar dela para que desabrochem em seu próprio processo.

É preciso lembrar que a encíclica dirige-se aos responsáveis pela aplicação e ensinamento da doutrina cristã. Neste capítulo, aborda especificamente o argumento de que a autoridade pública é necessária para impedir os abusos no trabalho. A Igreja é considerada moralmente responsável para intervir também nesse campo.

Embora esteja inserida nas relações de trabalho, a criança não deve, no entanto, entrar na oficina antes de ter adquirido, com a idade, as forças necessárias para tanto, pois é como uma planta tenra que poderá murchar com o trabalho. A idade desenvolve as forças, e o trabalho precoce faria murchar a planta. Com isso, a criança deixaria de ter acesso à educação.

A metáfora da planta ajuda a construir uma idéia de criança enquanto definição dos cuidados de que ela necessita. Contudo, também a desvincula das relações de identidade, do mundo humano. A flor da Rerum novarum é frágil por seu pequeno tamanho e pouca força; faz parte de uma ordem social composta por uma hierarquia que começa com o indivíduo, 
passa pela família, pela sociedade doméstica e pela fábrica e chega às relações de trabalho, às relações de classe, às relações políticas e, por fim, às relações com a divindade.

Como uma planta, a criança já possui tudo o que vai se desenvolver nela, embora precise dos cuidados dos adultos.

\section{Os rostos das crianças na Encíclica Rerum novarum}

Entre todos os aspectos doutrinários e filosóficos envolvendo as questões das condições dos operários que são apresentados na Rerum novarum, é no espaço do trabalho, na fábrica, que essa encíclica estabelece claramente uma especificidade pública para a criança. As condições de trabalho ali referidas a destacam especialmente por seu tamanho, sua pouca força e pela metáfora de uma planta ainda tenra que murcharia quando tomasse parte das práticas ali existentes.

Tal fato poderia levar-nos a ver a encíclica como uma carta sobre a condição dos operários, escrita pela Igreja Católica, e não como um documento escrito especialmente para se referir à criança.

Aceitar tal proposição equivaleria a menosprezar a importância que, naquela época, a Igreja e a fé tinham para as pessoas enquanto orientação para estarem no mundo. E também pressupor que a Igreja Católica iria dedicar, num documento público dirigido aos responsáveis pelas pastorais ou pela evangelização, algo que não estivesse em sintonia com o debate ou com as preocupações das pessoas naquela época.

$\mathrm{O}$ aspecto referente especificamente à criança diz respeito à entrada desta nas fábricas, para trabalhar. Aspecto de atualidade na época da encíclica, não pela criança em si ou mesmo pelo trabalho infantil, tal como o discutimos atualmente, uma vez que já se sabe que as crianças trabalham desde épocas anteriores, mas especialmente pelas mudanças nos modos de relações de trabalho anteriormente estabelecidos.

A encíclica fala das condições de exploração a que são submetidos os operários e tece considerações, fundamentadas na doutrina cristã, sobre qual deveria ser a conduta dos ricos, dos pobres e do Estado. A usura e a ganância de alguns, somadas às transformações trazidas pelos novos tempos (industrialização), afirma-se ali, têm levado crianças e mulheres para dentro das fábricas. 
A recomendação é que não se exija deles, e especialmente no caso das crianças (o que deverá ser seguido à risca), a mesma carga de trabalho exigida de um homem no pleno uso de sua força física. Os rostos da criança da Rerum novarum são definidos pelo seu tamanho e pela sua força. A criança é pequena e destituída de força física. O que define os limites do seu período de infância é sua capacidade de alcançar o livre-arbítrio.

A encíclica recomenda que adultos, em geral, e também o Estado não permitam a entrada da criança na fábrica até que a idade tenha desenvolvido sua força física e mental; do contrário, como uma planta ainda tenra, ela se verá murchar e dar-se-á cabo de sua educação.

A Rerum novarum fala assim de um lugar impróprio para a criança estar, um argumento que precisa ser reforçado com a metáfora da planta, uma vez que não bastaria mencionar apenas a crueldade do trabalho de um ser pequeno e fraco dentro da fábrica. Parece-nos que as condições de exploração e crueldade ligadas especificamente ao ambiente do trabalho trazem prescrições para adultos e para as instituições voltadas para a criança.

Vejamos. A Encíclica Rerum novarum apresenta argumentações favoráveis ao direito da propriedade privada, seguindo o que a Igreja entende por ordem natural das coisas.

A família é definida como uma sociedade doméstica e anterior à sociedade civil, devendo por isso ter direitos absolutamente independentes do Estado. O direito à propriedade privada, reivindicado para o indivíduo, é estendido para o homem, quando constituído chefe de família, pois é nessa sociedade doméstica que ele conquista a condição de pessoa humana.

É através dos filhos, motivo da constituição da família, espelhos da fisionomia do pai e uma espécie de prolongamento de sua pessoa, que a ordem natural das coisas se estabelece ("porque os filhos são alguma coisa de seu pai - Santo Tomás de Aquino").

O rosto da criança aparece num retrato de família. É o rosto de um encadeamento natural da condição humana. A criança faz parte da família, ocupa um lugar singular, é ela, como filho, que eleva o homem à condição de pessoa humana.

Por estar sob o governo do pai para todas as questões referentes aos seus fins imediatos e a sua conservação, a sociedade doméstica deve ter direito igual aos da sociedade civil. A 
criança é a criança da família e não da sociedade civil. É da sua entrada na fábrica, da sua entrada na ordem capitalista, que ela deve ser protegida.

O Estado só poderá intervir na sociedade doméstica para restabelecer os direitos mútuos, em situações desesperadoras, visando fortalecer tais direitos, protegê-los, defendê-los, como convém.

A autoridade paterna deve ser preservada, pois fundamenta-se na ordem natural. A criança não tem idade, e a condição de filho (a tutela paterna) permanece até que este alcance o livre-arbítrio, quando se agregará e incorporará à sociedade civil por intermédio da família.

Temos três rostos na Rerum novarum: o rosto da criança no retrato da família, o rosto da criança pequena e fraca, e a metáfora da planta tenra. É com esses rostos que a criança ganha caráter público, entra numa definição de uma orientação religiosa e pastoral. Os outros aspectos lhe são subjacentes. A criança ocupa, assim, um lugar na ordem natural das coisas.

A carta encíclica não refere outros espaços sociais para a criança além do espaço da família e é com bastante cuidado que se dirige a ela e a considera dentro da nova ordem que traz ameaças.

\section{B. A Declaração de Genebra sobre os direitos da criança}

A Declaração de Genebra sobre os direitos da criança foi assinada em 26 de setembro de 1924 pela Liga das Nações. Por se tratar do primeiro documento sobre a criança, assinado no contexto de um organismo governamental internacional, revela alguns aspectos importantes na construção da concepção de criança, pois pela primeira vez esta aparece destacada do seu contexto.

A Declaração é composta por um preâmbulo e por quatro artigos que estabelecem linhas gerais de conduta para com as crianças. Foi apresentada por uma organização de caridade, a International Union for Child Wellfare. Essa organização, que buscava meios para assistir as crianças na Primeira Guerra Mundial, coordenada por Eglantyne Jebb, da organização caritativa Save the Children, elaborou o texto com o objetivo de chamar a atenção para o fato de que, independentemente de sua nacionalidade, as crianças não deveriam sofrer com 
a guerra. O texto foi aprovado praticamente na íntegra na quinta assembléia da Liga das Nações.

No preâmbulo da Declaração reitera-se que "os homens e mulheres de todas as nações reconhecem que a humanidade deve dar à criança o que existe de melhor, afirmam seus deveres, a despeito de qualquer consideração de raça, nacionalidade ou crença" (grifo nosso).

A Declaração estabelece uma relação de equivalência entre o direito da criança e os conteúdos prescritos para os adultos na sua relação com ela. Dessa forma, podemos dizer que a criança tem, com inscrição oficial, governamental e internacional, a marca de um relacionamento, de prescrições implícitas na palavra “dever”, para os adultos.

O texto retrata uma criança que tem direito ao desenvolvimento. Identifica necessidades na criança e prescreve as formas de se lidar com elas e resolvê-las.

Art. 1. A criança tem o direito de se desenvolver de maneira normal, material e espiritualmente. ${ }^{2}$

O desenvolvimento normal é a chave do direito. Trata-se de uma normalidade tanto material como espiritual, dois termos tradicionalmente opostos, pois em geral se distingue o que é da matéria (do latim mater, mãe) e o que é do espírito. Nesse caso, concebe-se uma criança feita de corpo e alma. A tradução do texto original revela que o direito foi traduzido por "ter a possibilidade", ser colocado na possibilidade por alguém.

Art. 2. A criança que tem fome deve ser alimentada, a criança doente deve ser tratada, a criança retardada deve ser encorajada, o órfão e o abandonado devem ser abrigados e protegidos. (grifos nossos)

O texto dirige-se diretamente à criança que tem fome, doença, retardo que está na orfandade ou no abandono, e silencia sobre as que não têm essas necessidades. É essa a criança do documento, a que tem necessidades.

\footnotetext{
${ }^{2}$ No original: "L'enfant doit être mis en mesure de se développer d'une façon normale, matériellement et spirituellement", em tradução livre: "A criança deverá ter a possibilidade de se desenvolver de uma forma normal materialmente e espiritualmente".
} 
O emprego da voz passiva no trecho da sentença: "deve ser alimentada, deve ser tratada, deve ser abrigada", não é casual. Se a idéia é resolver a necessidade da criança, poder-se-ia também empregar a voz ativa e dizer, por exemplo, que a criança com fome deve alimentar-se ou que a criança doente deve buscar tratamento. Ao fazê-lo, o resultado seria o mesmo, o que mudaria seria a concepção de criança. O que faz a diferença é que, neste último caso, a criança seria sujeito, ao passo que no texto da Declaração ela é vista como objeto da ação do outro.

Tal forma de apresentação leva ao caráter prescritivo. Esse documento, que é internacional e inaugura uma série de documentos no contexto das organizações internacionais, chama a atenção para uma criança indefesa, apresenta-a como objeto de uma ação desencadeada por sua própria necessidade, por um outro.

A seguir a Declaração nos fala:

Art. 3. A criança deve ser preparada para ganhar a vida e deve ser protegida contra todo o tipo de exploração.

A criança deve ser preparada para ganhar a vida, ou seja, ela ainda não possui essa capacidade. Nesse artigo, a prescrição dirige-se a todas as crianças, isto é, apresenta uma condição geral para todas as crianças, sem identificar necessidades, como no anterior. Pode-se dizer o mesmo acerca da proteção contra todo o tipo de exploração. A criança da Declaração deve ser preparada para ganhar a vida e protegida da exploração.

Não se proíbe o trabalho da criança como forma de sustento próprio e, nas entrelinhas, podemos perceber que também não se proíbe a exploração, mas procura-se proteger a criança contra ela. Essa sutileza mostra a passividade associada à visão de criança e ao mesmo tempo um afastamento desta do mundo: o trabalho explorador pode continuar, mas ela deve ser protegida. A ação é especificamente voltada para a criança e, mais do que isso, destacada, descolada da realidade, de todas as questões envolvidas com o trabalho das crianças, já em épocas anteriores à própria Declaração.

O quarto e último artigo nos diz que:

Art. 4. A criança deve ser educada dentro do sentimento de que suas melhores qualidades devem ser postas a serviço de seus semelhantes. (grifos nossos) 
As prescrições aqui também são individuais: a idéia da passividade pressupõe que se deva educar a criança a pôr suas melhores qualidades a serviço dos outros. O tom autoritário é evidente, tanto pelo caráter prescritivo quanto pelo "a serviço", que tem uma conotação de subalternidade que coloca a criança numa condição de inferioridade.

Os quatro artigos da Declaração de Genebra descrevem uma criança que tem necessidades, que deve ser satisfeita, protegida da exploração do trabalho, que deve ser preparada para o trabalho e que deve ter a possibilidade (concedida pelos adultos) de se desenvolver de maneira normal de corpo e alma.

Segundo Ennew (1999), a Declaração de Genebra inscreve a criança como um sujeito de direito e não como um object of concern.

Essa Declaração foi escrita pela organização caritativa Save the Children e serviu de orientação para seu trabalho com crianças na Inglaterra e em outros países. Em contrapartida, a Rerum novarum, como vimos, chamava a atenção para a organização da sociedade em associações, ou seja, reconhecia o direito à propriedade privada e convidava a um tipo de organização dos trabalhadores fundada nessa marca.

No esforço de desfamiliarização com o tema dos direitos da criança, podemos observar que as declarações internacionais destacam a criança e suas necessidades, afirmando que elas devem ser preenchidas por adultos, sem, no entanto precisar quem são eles. Inauguram, assim, um novo vetor nas relações entre adultos e crianças, prescrições dadas pela lei. Contudo, não podemos supor que esses documentos estivessem preocupados com os direitos da criança como os conhecemos hoje.

\section{Os Rostos das crianças da Declaração de Genebra, 1924.}

No início do século XX, um dos problemas que se colocavam para a sociedade era levar as crianças para a escola. Das primeiras legislações sobre o trabalho até a escolarização compulsória, muitos anos se passaram. O início do século XX é descrito como um período de florescimento das ciências da criança, e a declaração de 1924 traz definiçõos de criança que são científicas junto a outras próprias dos movimentos "save the children". 
Os termos que se destacam para a definição de criança na Declaração de Genebra de 1924 são o desenvolvimento de seu corpo e da sua alma. Nessa Declaração, a palavra desenvolvimento é usada para definir um padrão normal para aspectos materiais e espirituais e criança tem o direito de se desenvolver.

Algumas condições ou situações podem levar a criança a sair desse padrão, e é dessas crianças que a declaração fala. A fome, a doença, o retardo e a orfandade são aspectos destacados da vida das crianças para os quais se prescrevem (a criança que tem fome deve ser..., por exemplo) formas de conduta, alimentação, tratamento, encorajamento e abrigo e proteção, respectivamente.

A Declaração menciona especificamente as crianças que se encontram nessas condições, relacionando a palavra proteção à orfandade e ligando outras condutas às condições das próprias crianças.

A Declaração de Genebra descreve uma criança que segue um desenvolvimento normal. Embora a normalidade e esse desenvolvimento não sejam explicitados, os termos sugerem a configuração de um estado natural num conjunto de necessidades identificadas nas crianças. Porém, enfatiza-se a sua projeção no futuro: ela deve ser preparada para ganhar a vida e, no presente, deve ser protegida contra todo o tipo de exploração.

A proteção aparece ligada não só aos órfãos e abandonados, que devem ser abrigados, mas também àquelas crianças que são exploradas no trabalho. Sutilmente, portanto, essa Declaração considera que a criança trabalhadora também é necessitada, pois o conjunto das necessidades das quais emanam as prescrições é localizado na criança e esta deve ser protegida da exploração no trabalho.

A educação é outro aspecto que define a criança na Declaração. A criança deve ser educada, e isso está na ordem das prescrições. Tal como a criança que tem fome deve ser alimentada, ela também deverá ser educada, na ordem das necessidades, e não poderá ficar sem receber educação. Tal educação terá o objetivo de orientar a criança a colocar suas melhores qualidades a serviço dos seus semelhantes.

O tom da Declaração é prescritivo para os adultos que deverão executá-la. O direito da criança é o direito de se desenvolver, e o desenvolvimento tem padrão normal, material e 
espiritualmente. A capacidade da criança é a capacidade de se desenvolver; outros aspectos são prescritos para condutas dos adultos.

A Declaração não faz nenhuma menção à família, a não ser nas palavras órfão e abandonado; a idade da criança; a adolescência e a questões jurídicas. Além disso, a Declaração também não diz quando a criança deixa de ser criança.

Essa Declaração traz uma criança pública. Não se trata exatamente de estabelecer uma separação entre o que é público e o que é privado, e sim de traçar as regras gerais de como a criança, uma universalidade, deve ser tratada e o relacionamento das crianças com os adultos é marcado pela submissão. O relacionamento dos adultos com as crianças é mediado por prescrições

Em suma, a Declaração de Genebra fala de um relacionamento entre adultos e crianças como um dever. Cabe aos adultos providenciar o melhor para as crianças, mas isso deverá ser feito para atender necessidades localizadas na criança: a fome, o abandono, a doença, o retardo. A criança também deve ser preparada para ganhar a vida e protegida da exploração no trabalho.

A Declaração de Genebra apresenta-nos, portanto, três rostos de criança: o rosto das necessidades, o rosto feito de matéria e espírito, o rosto do desenvolvimento normal, que encerram a impessoalidade, que é nova no seu destacamento do mundo dos adultos. A criança é descrita na voz passiva e em nenhum dos artigos se nomeia o sujeito da ação de alimentá-la, abrigá-la ou prepará-la para o trabalho. Para além de um objeto, essa Declaração descreve um objeto sem referências. A única referência é a seus semelhantes, forma impessoal de indicar pessoas que estariam exercendo funções (que hoje entendemos) tão importantes quanto à satisfação de necessidades.

É a descrição das condutas que emanam das relações dos adultos com as crianças necessitadas, mais do que a universalidade das necessidades identificadas, que faz a impessoalidade do relacionamento. Essa Declaração trata de estabelecer o que é próprio da criança e o que é apropriado para ela, os seus direitos. 


\section{A Declaração Universal dos Direitos da Criança}

A Declaração Universal dos Direitos da Criança foi promulgada pela Organização das Nações Unidas (ONU) em 20 de novembro de 1959 e é constituída por um preâmbulo e por 10 princípios.

O preâmbulo considera os princípios existentes anteriormente na Carta das Nações, na Declaração Universal dos Direitos do Homem, a falta de maturidade psíquica e intelectual da criança, a necessidade de proteção especial para as suas necessidades, o fato de essa proteção já ter sido enunciada em 1924 na Declaração de Genebra sobre os Direitos da Criança, na Declaração Universal dos Direitos do Homem e também pelas instituições especializadas e pelas organizações internacionais consagradas ao bem-estar da infância.

Os princípios enunciam cuidados e proteção especial para a criança por considerar a sua condição peculiar de desenvolvimento, e afirmam que os direitos da criança devem ser considerados com universalidade, objetividade e igualdade.

Com a aparição da criança na Declaração Universal dos Direitos do Homem (1948), após a Segunda Guerra Mundial, os rostos das crianças ganham a moldura num quadro ou cenário público muito mais definido. Sua aparição nos termos da vida social é mais explícita, bem como os itens dos artigos que falam de sua inserção como parte da nação.

Art. 25. Parágrafo 2. A maternidade e as crianças receberão atenção especial e assistência. Todas as crianças, tidas ou não no casamento, deverão receber a mesma proteção.

Esse parágrafo do artigo 25 da Declaração Universal dos Direitos do Homem usa dois contextos da vida das crianças, a maternidade e o casamento, duas possibilidades de vinculação à vida social, apropriadas moralmente para a época. Ou seja, trata-se da proteção da criança dentro de uma ordem moral. Especialmente aqui, deixa-se de lado a questão da união dos pais ser ou não legal para se destacar a criança da situação e protegêla. Valoriza-se, assim, o laço de filiação, mas a criança só passa a receber o mesmo benefício da assistência social graças ao reconhecimento, pelos organismos internacionais, da imaturidade de seu desenvolvimento quando pequena.

Foi nessa época que, em alguns países, se estenderam a todas as crianças alguns serviços sociais e benefícios como maternidades e clínicas de puericultura e pensões. Os Estados 
Partes reafirmaram sua fé no valor do ser humano e na possibilidade do progresso social, em melhores condições de vida dentro de liberdade "mais ampla" e na Declaração Internacional dos Direitos do Homem. O texto da Declaração dirige-se aos "pais, homens e mulheres em sua qualidade de indivíduos, e as organizações voluntárias, as autoridades locais e os Governos nacionais" para que se empenhem para a sua observância mediante medidas progressivamente instituídas.

$\mathrm{Na}$ Declaração Universal dos Direitos da Criança, outros aspectos são escolhidos para a definição de criança. Outros atores surgem, e nomeadamente a criança passa a ser definida no contexto da governabilidade das nações envolvidas.

Vejamos o que dizem os princípios:

Princípio I. A criança desfrutará de todos os direitos enunciados nesta Declaração. Estes direitos serão outorgados a todas as crianças, sem qualquer exceção, distinção ou discriminação por motivos de raça, cor, sexo, idioma, religião, opiniões políticas ou de outra natureza, nacionalidade ou origem social, posição econômica, nascimento ou outra condição, seja inerente à própria criança ou à família. (grifos nossos)

Esse princípio aponta para a diversidade das crianças ao falar de raça, nacionalidade, cultura, entre outras coisas, e afirma a igualdade entre elas no que diz respeito aos direitos. Nesse sentido, as crianças são iguais e deverão ser tratadas sem preconceito ou discriminação. O direito pode, segundo o texto dessa Declaração, igualar as crianças, apesar de todas as diferenças. Para além da experiência pessoal, o direito universaliza a infância.

Princípio II. A criança gozará de proteção especial e disporá de oportunidades e serviços, a serem estabelecidos em lei por outros meios, de modo que possa desenvolver-se física, moral, espiritual e socialmente de forma saudável e normal, assim como em condições de liberdade e dignidade. Ao promulgar leis com esse fim, a consideração fundamental a que se atenderá será o interesse superior da criança. 
A criança descrita nesse artigo desenvolve-se. Esse desenvolvimento é físico, moral, espiritual e social. Não se trata de um desenvolvimento único, mas sim composto por vários aspectos. São esses diferentes aspectos que formam a identidade da criança da Declaração Universal dos Direitos da Criança: o ser em desenvolvimento.

O desenvolvimento é algo que acontece com a criança, na criança. É preciso criar algumas leis, serviços e oportunidades para proteger esse desenvolvimento e permitir que ele ocorra.

A criança tem um interesse superior, que deverá ser considerado na promulgação das leis. O Estado relaciona-se de forma direta com a criança, ou ao menos com o que é relatado como seu superior interesse. O interesse da criança é superior, contribui para que as decisões do Estado, concernentes ou não a ela, sejam vistas como superiores.

A criança apresentada aqui, além de viver no seu processo de desenvolvimento, tem o Estado para cuidar de seus interesses superiores.

Princípio III. A criança tem direito, desde o seu nascimento, a um nome e a uma nacionalidade.

A criança é identificada com nome e nacionalidade. Como ser singular, deve possuir registro de nascimento e pertencer a uma nação. É, portanto, parte da nação.

Princípio IV. A criança deve gozar dos benefícios da previdência social. Terá direito a crescer e desenvolver-se em boa saúde; para essa finalidade deverão ser proporcionados, tanto a ela, quanto a sua mãe, cuidados especiais, incluindo-se a alimentação pré e pósnatal. A criança terá direito de desfrutar de alimentação, moradia, lazer e serviços médicos adequados. ( grifos nossos)

O Estado se relaciona com a criança também através da previdência social e deve prover cuidados especiais, inclusive alimentação, também para a gestante. A criança desse artigo tem direito não só aos benefícios da previdência, mas o direito a crescer e se desenvolver em boa saúde, pois, para isso, e só para isso, poderá desfrutar dos benefícios de previdência social. As duas proposições não querem dizer a mesma coisa, na medida em que não há uma conexão direta entre criança e previdência. A conexão é feita pela sua saúde e pela sua condição de ligação com sua mãe. 
Ela tem, contudo, direito de desfrutar de alimentação, lazer, moradia e serviços médicos adequados. Estes últimos não são claramente formulados como direitos à previdência social.

A criança descrita nesse artigo terá de forma clara e afirmativa cuidados especiais para si e sua mãe durante a gestação e os primeiros tempos de sua vida. O Estado, através da previdência, tem um compromisso com a sua boa saúde.

Princípio V. A criança física ou mentalmente deficiente ou aquela que sofre algum impedimento social deve receber tratamento, a educação e os cuidados especiais que requeira o seu caso particular. ( grifos nossos)

A Declaração tem um artigo também sobre a criança deficiente ou com impedimentos sociais e prescreve a ação de educação e cuidados especiais conforme o caso particular de cada uma.

A palavra deficiente (do latim déficit, falta) passa a ser adotada pela ciência em 1959, e a Declaração reconhece o termo cunhado pelo saber médico e psicológico e de uso politicamente correto.

Algumas crianças são diferenciadas das outras porque foram assim identificadas pelos saberes educacionais, médico e psicológico. Outros termos circulavam, tais como: aleijado, abobado, retardado, por exemplo. A criança deficiente deve ser tratada pelas práticas educativas, deve ser conhecida por suas particularidades e a partir daí o seu "caso" define o resto.

Princípio VI. A criança necessita de amor e compreensão, para o desenvolvimento pleno e harmonioso de sua personalidade; sempre que possível deverá crescer com o amparo e sob a responsabilidade de seus pais, mas em qualquer caso, em um ambiente de afeto e segurança moral e material: salvo circunstâncias excepcionais, não se deverá separar a criança de tenra idade de sua mãe. A sociedade e as autoridades públicas terão a obrigação de cuidar especialmente do menor abandonado ou daqueles que careçam de meios adequados de subsistência. 
Convém que se concedam subsídios governamentais, ou de outra espécie para a manutenção dos filhos de famílias numerosas.

A criança da Declaração é um ser que necessita de amor e compreensão para desenvolver plenamente sua personalidade. Aqui podemos ter uma idéia do peso do conhecimento psicológico, especialmente das teorias do desenvolvimento na construção da criança universal.

A criança da Declaração precisa do amor e da compreensão de seus pais para desenvolver a sua personalidade de maneira harmoniosa. Os únicos agentes nomeados são os pais, de quem a criança tem necessidade. Porém, logo em seguida o texto trata de definir que a necessidade é de segurança moral, material e afetiva, que poderia ser fornecida pela família, mas também poderia ser encontrada num ambiente assim organizado.

A criança também pode ser um menor abandonado, ou carente dos meios de subsistência adequados. A família pode falhar como o local adequado, pode abandonar, pode não ter meios apropriados para prover à subsistência de seus filhos. Quando isso acontece, a criança torna-se um menor, termo jurídico para os que estão fora da família. Para eles, a ação do Estado deve ser de proteção.

As famílias de prole numerosa poderão receber subsídios para a manutenção de seus filhos. Aqui o termo empregado destoa do tom da Declaração. A palavra manutenção tem o significado de sustentar, de prover o necessário à subsistência e também de conservação. Assim, veicula-se ao mesmo tempo a idéia de que um número elevado de filhos pode trazer despesas para o Estado e de conservadorismo.

Princípio VII. A criança tem direito a receber educação escolar, a qual será obrigatória e gratuita, ao menos nas etapas elementares. Dar-se-á à criança uma educação que favoreça sua cultura geral e lhe permita - em condições de igualdade de oportunidades - desenvolver suas aptidões $e$ sua individualidade, seu senso de responsabilidade social e moral, chegando a ser um membro útil à sociedade. O interesse superior da criança deverá ser o interesse diretor daqueles que têm responsabilidade por sua educação e orientação; tal responsabilidade incumbe, em primeira instância, a seus pais. A criança deve desfrutar plenamente de jogos e brincadeiras, os quais deverão estar dirigidos para educação; a 
sociedade e as autoridades públicas se esforçarão para promover o exercício deste direito.

A educação da criança é de responsabilidade dos pais. Essa criança deverá obrigatoriamente receber uma educação escolar cujo objetivo seja desenvolver suas aptidões e sua individualidade, seu senso de responsabilidade social e moral. A meta é fazer dela um membro útil à sociedade, o que ela ainda não é. Esse artigo fala da individualidade da criança, mas não de sua personalidade.

Os responsáveis por sua educação conhecerão seus interesses superiores e por eles se orientarão nas ações educativas, nas quais foram incluídos seus jogos e brincadeiras.

Aqui temos uma criança que vai obrigatoriamente para a escola, espaço privilegiado para o seu desenvolvimento, onde aprenderá a ser um cidadão útil para a sociedade. Seus jogos e brincadeiras são reconhecidos como um desfrute, mas devem ser orientados para essa finalidade.

Esse artigo parece estar dirigido para pais e para o Estado, e seu texto é uma negociação entre a manutenção da responsabilidade pela educação da criança por eles, por um lado, e a obrigatoriedade de receber educação escolar, apresentada pelo Estado. O direito aqui é resolução da negociação entre pais e Estado.

Os pais e educadores conhecem os interesses superiores dessa criança.

Princípio VIII. A criança deve - em todas as circunstâncias - figurar entre os primeiros a receber proteção e auxílio.

Princípio IX. A criança deve ser protegida contra toda forma de abandono, crueldade e exploração. Não será objeto de nenhum tipo de tráfico. Não se deverá permitir que a criança trabalhe antes de uma idade mínima adequada; em caso algum será permitido que a criança dediquese a, ou a ela se imponha, qualquer ocupação ou emprego que possa prejudicar sua saúde ou sua educação, ou impedir seu desenvolvimento físico, mental ou moral. 
A criança é protegida contra o abandono, a crueldade e a exploração e qualquer tipo de tráfico. A criança só poderá trabalhar quando tiver idade adequada, e esse trabalho deverá estar condicionado a não prejudicar a sua saúde ou educação.

O desenvolvimento físico, mental e moral é desvinculado da saúde e da educação. O trabalho tem efeito direto sobre o desenvolvimento, no caso impedindo-o. O texto enuncia que a criança poderia dedicar-se a ou poderia ser-lhe imposto algum trabalho.

Princípio X. A criança deve ser protegida contra as práticas que possam fomentar a discriminação racial, religiosa ou de qualquer outra índole. Deve ser educada dentro de um espírito de compreensão, tolerância, amizade entre os povos, paz e fraternidade universais e com plena consciência de que deve consagrar suas energias e aptidões ao serviço de seus semelhantes.

A criança vive num mundo onde existe a discriminação racial, religiosa e de outras índoles e deve ser protegida contra as práticas que as fomentem. Sua educação deve acontecer dentro de um espírito de compreensão entre os povos.

A criança pode ter consciência quando se trata de consagrar suas energias e aptidões a serviço de seus semelhantes.

\section{Os Rostos das Crianças na Declaração Universal dos Direitos da Criança, 1959.}

A criança é descrita nos termos de imaturidade física e mental. Por ser imatura, ela deve necessariamente ser objeto de proteção e de cuidados especiais, inclusive de proteção legal antes e depois do nascimento. No preâmbulo da Declaração, tanto os aspectos escolhidos para a definição quanto à estratégia pública para se lidar com a criança física e mentalmente imatura estão fundamentados nos enunciados das declarações anteriores. A única novidade é a citação das agências especializadas e das organizações internacionais interessadas no bem-estar da criança.

Em outras palavras, não se trata mais, como na Declaração Internacional dos Direitos do Homem, de um contexto a ser legislado (maternidade ou nomeação), e sim de uma qualificação ampla e totalizadora da criança. Ser criança é ser física e mentalmente imaturo. 
A criança não tem idade nessa Declaração. A partir da qualificação principal de imaturidade física e mental, ela adquire diversidade, cultura, raça, religião, família, nacionalidade, origem social, posição econômica, entre outras. Essas diversidades são igualadas no tratamento a ser dado às crianças: nenhuma discriminação, exceção ou distinção deverá ocorrer, uma vez que todas são crianças (física e mentalmente imaturas). Esses rostos de crianças não estão misturados por acaso. Os tratamentos diferenciados que uma criança pertencente à determinada religião recebe não se justificam, mas não estão determinados pelas mesmas condições caso ela apresente condição econômica diferente de outra criança da mesma religião.

A partir daí, talvez possamos nos dar conta da complexidade da noção de criança e, especialmente, observar que, nesse texto, as tensões, conflitos e desigualdades que imediatamente nos vêm à cabeça não estavam presentes na época em que essa Declaração foi promulgada. O estabelecimento de uma condição de humanidade para as crianças parece ser uma preocupação presente, bem como a inserção dos direitos delas numa hierarquia de conceitos científicos (imaturidade física e mental, por exemplo, são conceitos provenientes da Psicologia, especialmente de uma perspectiva evolucionista).

Pressupõe-se que o desenvolvimento deverá ocorrer de forma normal e saudável. Os termos que indicam como se dá esse desenvolvimento revelam a especialização do conhecimento sobre a criança. A forma como esse conhecimento está organizado nessa Declaração aponta para a identificação e constituição dos saberes que podem regular a vida das crianças. Assim, estas deverão ser protegidas, ganham serviços, oportunidades para que possam desenvolver-se física, moral, espiritual e socialmente, assim como em condições de liberdade e dignidade.

Tendo direito a um nome e a uma nacionalidade, a criança está presente no esforço de estabelecer o Estado-Nação.

O documento menciona explicitamente o "superior interesse da criança", que será exercido na formulação de leis: “Ao promulgar Leis com esse fim, a consideração fundamental a que se atenderá será o superior interesse da criança". A criança tem uma relação direta com o Estado, mas não tão direta assim, uma vez que o "superior interesse da criança" era algo a ser determinado por um poder supremo, o poder maior, justamente do Estado. 
Também é com o Estado a próxima relação que a criança estabelece como direito, o direito à previdência social. Esse direito está ligado ao seu desenvolvimento e crescimento (que são nomeados separadamente), que devem acontecer com saúde.

Como a Declaração anterior, esta também fala da criança deficiente, mas utiliza uma terminologia da literatura médica que não era empregada na outra (falava-se ali de criança retardada). Essa criança, bem como a que tem algum impedimento social, deverá receber um atendimento particularizado, conforme as necessidades que o seu "caso" requeira. É evidente aqui a pressuposição de um desenvolvimento natural. A criança que, por um ou outro motivo, não consegue ter esse desenvolvimento natural, transforma-se em um "caso", cujo significado hegemônico é definido pela medicina, pela patologia. Na Declaração anterior, a criança retardada deveria ser protegida; nesta, a criança é deficiente e se insere em outra categoria, a das prescrições dos tratamentos ou condutas especializadas. É como totalidade que ela deverá ser protegida.

O rosto da criança também é frágil: para o desenvolvimento pleno e harmonioso de sua personalidade (um termo definido pela Psicologia), ela necessita do amor e compreensão encontrados na família, especialmente ao lado da mãe. É nesse lugar que a criança deverá crescer, amparada pelos pais e sob a responsabilidade deles. Deve ali se desenvolver como um indivíduo autônomo, dotado de uma personalidade, possibilitada pelo contato amoroso e protetor da família.

A criança se desenvolve de diversas maneiras (tem uma personalidade). No preâmbulo da Declaração fala-se em desenvolvimento, e não em crescimento. Desenvolver adquire aqui um sentido da obrigação, de algo que deve acontecer por ser científico. Proteger, crescer ou ser criado, por exemplo, são formas consolidadas em tempos mais remotos.

Quando esse desenvolvimento não é possível, as autoridades públicas e a sociedade terão a obrigação (prescrição) de cuidar especialmente do menor abandonado ou dos que careçam dos meios adequados de subsistência (a criança abandonada ou sem recursos é um menor, termo comparativo que indica uma posição inferior a um referencial determinado). Algumas traduções oficiais brasileiras trazem o termo "menor abandonado", enquanto outras, também oficiais, preferem falar em "criança sem família”.

CADERNOS GESTÃo PÚBLICA E CIDADANIA, v. 12, N.51 - JUL./DEZEMBRO 2007 
Nessa Declaração, a criança tem direito a receber educação escolar. A educação será obrigatória (único ponto em que alguma coisa é prescrita para a criança) e gratuita (dever do Estado). As linhas gerais de como essa educação se dará estão também descritas na Declaração: a criança tem aptidões e individualidade, senso de moral e responsabilidade social, que a educação deverá desenvolver.

A finalidade é torná-la "um membro útil à sociedade". Tal responsabilidade incumbe a vários agentes: em primeira instância, aos pais e também aos outros que "têm responsabilidade sobre a sua educação e orientação".

Em suma, a educação tem finalidades, deve ser exercida de determinada maneira, há pessoas responsáveis por ela. As pessoas envolvidas nessa tarefa também devem levar em conta o superior interesse da criança na execução dessa responsabilidade.

Nessa Declaração, a criança também deve desfrutar de jogos e brincadeiras que deverão estar canalizados para a educação. A criança é identificada, portanto, por exercer atividades próprias de criança; é tratada como criança.

Ao longo dos seus dez princípios, a Declaração distribui responsabilidades e define ações e possibilidades das pessoas e do Estado em relação às crianças. $\mathrm{O}$ rosto de criança física e mentalmente imatura revelou-se capaz de conferir sentido a vários outros rostos apresentados nos outros documentos: necessidade, direitos, proteção, entre outras tantas prescrições. A Declaração também pode entendida como um texto relacional, na medida em que, ao definir a criança como física e mentalmente imatura, procura estabelecer também as relações possíveis e esperadas entre adultos e crianças.

A criança deverá ser a primeira a receber proteção e auxilio, em todas as circunstâncias.

Não se recomenda que a criança trabalhe e ela deverá ser protegida de qualquer tipo de exploração, crueldade e abandono. Embora não proíba o trabalho infantil, a Declaração obriga a freqüência à escola. Recomenda-se que a criança não trabalhe antes de uma idade mínima ou mesmo que não se dedique a nenhuma ocupação ou emprego que possa prejudicar sua saúde e educação ou impedir seu desenvolvimento físico, mental ou moral. Nas justificativas finais da recomendação encontramos argumentos bastante semelhantes aos descritos na encíclica Rerum novarum. 
A proteção da criança está ligada a palavras como abandono, crueldade, opressão, discriminação. Outras palavras, tais como direito, parecem estar ligadas a demandas feitas ao Estado. Outras prescrições falam sobre a forma como adultos devem se relacionar com as crianças ou mesmo orientar suas práticas em relação a elas.

Os rostos das crianças da Declaração de 1959 são rostos psicológicos, cuja saúde mental necessita de intenso cuidado e compreensão por parte dos pais e das instituições. São rostos definidos a partir de uma essencialidade, a imaturidade física e mental. Nesse documento, além de ser caracterizada como um estágio específico da vida humana, a criança ganha rostos definidos pela personalidade e especialmente pelo desenvolvimento normal. $\mathrm{O}$ ser imaturo tem um caminho a percorrer até se transformar no adulto.

A Declaração não menciona a idade e deixa de lado aspectos como marginalidade, mas assume uma posição claramente contrária ao trabalho das crianças, justificada por uma necessidade do desenvolvimento, e não mais pelo tamanho, como na Rerum novarum.

Ao rosto da criança física e mentalmente imatura, esse documento une muitos outros repertórios empregados anteriormente para dar sentido à criança que tem direitos. Aqui, o que é apropriado para as crianças, seus direitos, já não constitui apenas uma questão impessoal. Já não estamos diante de relacionamentos que satisfazem necessidades da criança, e sim de condutas que são apropriadas. A quantidade de prescrições aumenta e a criança passa a ocupar muito mais espaços da vida social. É dever moral do adulto responsabilizar-se pela criança. Já não basta dar o melhor de si para a infância; é preciso dar o correto, pois a criança é imatura, é frágil, tem personalidade e precisa de cuidados, é uma criatura vulnerável.

\section{Considerações finais.}

Os documentos internacionais descrevem algumas práticas com crianças apresentadas nos espaços públicos. Os documentos falam de direitos das crianças e também de prescrições que podem ser entendidas como aspectos relacionais. Por estarem articuladas nesse tipo de documento, tais prescrições sugerem que uma parte da construção universal da infância, aquela que se apresenta como lei, como normativa internacional, só poderá ser trabalhada 
em dimensões estatutárias, no cotidiano, se artificialmente fizermos valer um ou outro aspecto.

Não obstante a presença ubíqua da proteção da criança nas documentos existem também muitos aspectos sobre os quais eles silenciam e as prescrições mudam significativamente, busca-se mudanças nas relações com as crianças. Os documentos enfatizam as relações entre família e criança e entre família e Estado. A relação entre a criança e o Estado se constrói com diferentes rostos de criança, presentes em diferentes saberes sobre a criança. Nota-se que, a partir da Declaração dos Direitos Humanos, as crianças são consideradas como seres humanos, e nesse tipo de humanidade o que se valoriza é o vínculo de filiação. Bem antes, na Rerum novarum e na Declaração de Genebra, os direitos são apresentados com o sentido de obrigação dos adultos em relação a elas, e tal conceito não sofreu alterações significativas até os dias de hoje.

A criança dos direitos não é universalizada apenas na lei, mas também nos saberes. No entanto as práticas com crianças incluem outros relacionamentos que não estão exatamente previstos nas leis, mas que continuam fazendo História. Busca-se, assim, apontar a necessidade de trabalhos cooperativos não para as crianças, mas com as crianças, deixando de lado a universalidade, as condutas que submetem a criança, ou que criam a impessoalidade ou o distanciamento nos relacionamentos. 


\section{Referências Bibliográficas}

ARIÉS, P. História social da criança e da família. Rio de Janeiro: Guanabara, 1981. 279p.

BERTUOL, C. A crianca e o Estatuto da Criança e do Adolescente: um estudo sobre a polissemia da criança nos espaços públicos. 2003. 200f. Dissertação (Mestrado em Psicologia Social) Programa de Estudos Pós-Graduados em Psicologia Social. Pontifícia Universidade Católica de São Paulo.

BOYDEN, J. Social and cultural meanings of childhood. Journal of the Society of International Development, n. 1, p. 18-22. 1996

BRAUDEL, F. Escritos sobre a História. São Paulo: Perspectiva, 2007. 290p

—. Reflexões sobre a História. São Paulo: Martins Fontes, 2002. 402p.

ENNEW, J. The history of children's rights: whose story? Cultural Survival Quarterly, vol. 24, n 2.p. 2000

HAMMABERG, T. The convention on the rights of the child: new attitudes to children. Journal of the Society for International Development, 1, 1996.

KNUTSSON, K. E. Children and the future: worthy causes or worthy citizens? Journal of the Society for International Development, 1, 1996.

LEÃO XIII. Carta Encíclica Rerum novarum: sobre a condição dos operários. São Paulo: Loyola, 1991. (Col. Documentos Pontifícios). 38p

LIGA DAS NAÇOES. Déclaration des Droits de l'Enfant [Déclaration de Géneve]. 1924. Disponível em: http://www.legis.acjnet.org/loisInt/html/lois3 1.html

ORGANIZAÇÃO DAS NAÇÕES UNIDAS (ONU). Declaração Universal dos Direitos da Criança. 1959. Disponível em: http://www.dprf.gov.br/leis.asp

SEDA, E. A criança e a sua convenção no Brasil. São Paulo: Conselho Regional de Psicologia, 2000 .

SPINK, M. J. (org.). Práticas discursivas e produção de sentidos no cotidiano: aproximações teóricas e metodológicas. São Paulo: Cortez, 1999, 296p.

SPINK, P. Análise de documentos de domínio público. In: SPINK, M. J. P. (org.), op. cit.

Artigo recebido em: 10/07/ 2007 e aceito em 12/09 /2007 